\title{
Postgraduate supervision and the early stages of the doctoral journey
}

\author{
Samuel Herbert Baligidde ${ }^{1}$ *
}

(C) Uganda Martyrs University

\begin{abstract}
This article looks at two previous study reports on postgraduate supervision, views, and experiential as well as academic advice from other scholars. It presents the various perspectives on the central phenomenon relationship between the supervisor and the doctoral student at the initial stages of the $\mathrm{PhD}$ programme, arguments, suggestions and insights into the nature and substance of $\mathrm{PhD}$ supervision, early articulation of expectations and clarifying them; commitment to establishment of clear goals; and developing a study plan and time-table that are consistent with work. It also explores knowledge and a warm, supportive relationship; planning from the beginning, including research mapping and concept charting; proper time-management; and internalising the criteria for examination of a $\mathrm{PhD}$ thesis, capacity to relate the research topic to the discipline; encouraging the use of writing as a voyage of discovery. It argues that all these are vital to sustaining the momentum and completion of a $\mathrm{PhD}$ by research. It concludes that postgraduate supervision requires that supervisors and doctoral students by research clarify and discuss their expectations at the beginning and on a continuous and regular basis; that differences in perception or procedure can present the supervisor and the student with debilitating challenges that can impede progress and eventually fail to get the coveted $\mathrm{PhD}$.
\end{abstract}

Key words $\cdot$ Expectations $\cdot$ Timely completion $\cdot$ Incongruence

\section{Introduction}

This article seeks to explore the nature of the challenges and opportunities of supervision. In this regard, it seeks to answer the following questions: Why are traditional supervisor-centric relationships increasingly being challenged? What elements are important in creating a positive supervisory relationship between the supervisor and the student? What strategies can be adopted to address disparities in the expectations of the supervisor viz-a-viz the student? What are the challenges of a supervisor's personal guidance of the student? Why are supervisors encouraged to take an active role in the teaching and research? What can be done to enhance timelycompletion? The aim is to develop a deeper insight into the various aspects of postgraduate supervision as related to getting doctoral students started on the journey.

\footnotetext{
${ }^{1}$ Uganda Martyrs University, * sbaligidde@umu.ac.ug
} 
This knowledge may help students to endure the challenges, demands and expectations of a $\mathrm{PhD}$ programme. It partly draws on the author's own personal experience of a doctoral journey. However, it is difficult to arrive at a practical understanding of postgraduate supervision without grounding it in the experiences and expertise of those who have gone through the process. Therefore, reports of previous studies on various aspects of postgraduate supervision are examined with the aim of using them as sources of data. Unstructured participant observation results have been reduced to categories of data for analysis. In this article, an attempt is made to relate what I have so far read and been told by my two supervisors as well as some other faculty well-wishers to my own initial experiences.

Montuori and Donnelly (2013) highlighted the importance of immersing oneself in the literature to situate properly in "a larger ecology of ideas" and to encourage the development of a participatory attitude. They suggest that as part of their broader scholarship, participation in conferences and writing book reviews, among other activities, help the student develop a participatory attitude. They become familiar with the research on creativity and the influence of articulation, diffusion and implementation of ideas by other scholars. It is, true, in both the sample and the population, that participation is part of the broader learning process of a $\mathrm{PhD}$ student. A neophyte cannot be expected to quickly situate in the kind of large ecology of ideas exuded by professors or experienced academics. Nonetheless, participating in writing a book review of a recent work is incontestable advice. Writing exposes the research student to "creativity" which is variously defined as "discovery", "something new", "extending the boundaries of knowledge". In this context, this means relating previously unrelated ideas or themes to the creative process of (1) logic (2) idealinking (3) problem-solving and (4) free association, all leading to the formulation of a new theory (Montuori and Donnelly, 2013).

Hicks and Gullett (1976) describe it as the ability to look at things with a fresher and critical eye but others, such as Daniel (2018) calls it rigour using the TACT (explained as Trustworthiness, Auditability, Credibility, and Transferability) framework. Recent literature on postgraduate supervision supports his postulations. It is noteworthy that there is no controversy over the level of inquiry expected of a $\mathrm{PhD}$ student. As Moxham et al (2016) maintain, such academic rigour can be demonstrated by not only articulation, diffusion and implementation of ideas but writing a book review is also as effective in doing that as making a presentation at an academic forum. Since in the initial supervisor-student interactions doing things step-by-step is emphasised, a departure from such a norm would be tantamount to the kind of indiscipline capable of envenoming supervisor-student relations as will become apparent in the following review.

Postgraduate supervision success depends on articulating expectations about supervision and getting the gist of the matter right at the very start of the $\mathrm{PhD}$ journey. The problem though, is that if there is belief in the inevitability of conflict, then 'getting it right from the beginning' does not preclude the possibility of artificially- 
conceived or real discordance creeping in somewhere along the way or things getting complex thereafter. Given the variety of supervisory styles, the ways in which supervisors respond to student expectations are strongly influenced by their own philosophy of supervision and perception of the 'right path'. What happens when fundamental incongruence or trivial disparities in expectations occur? Coming from a professional negotiation and mediation background I wondered whether to employ some of the skills from those domains when the seemingly inevitable happened to me too but I decided that quality real or perceived in academic rigour was not negotiable and decided to use other means to go forward. If the doctoral committee fails to resolve the problem then the remaining alternatives are change of supervisors or in the extreme case self-supervision if allowed or feasible. A supervisor whose research methodology is particularistic and whose outlook leans towards the scientific tradition tends to emphasise quantitative approaches that focus on what he/she perceives as the right way. By contrast a student whose background leans towards the humanities and cognizant of the need for basic standards of quality assurance is more independent and will look at many possibilities of approaching the research problem. These two types are prone to develop fundamental discordancy.

This article examines issues related to (1) the articulation of expectations about supervision (2) timely-completion (3) separate student and supervisor expectations. It discusses the findings of an online study via Survey Monkey carried out in Australia (Moxham et al, 2013:345-354) in which a purposive sample of research higher degree supervisors and candidates in Australia, UK, Hong Kong and USA was selected. It looks at the mutual expectations in the postgraduate supervisory relationship and discusses the central phenomenon of supervisor-supervisee incongruence. The results of a qualitative case study generalisable to international research on postgraduate supervision, that followed a structured interview approach involving eliciting the perceptions of postgraduate doctoral supervisors and doctoral students with regard to supervision carried out at a research-intensive university in the USA (Friedrich-Nel and Mackinnon, 2016:161). The necessity for (1) frequent discussions (2) supervising the writing of a thesis (3) conviviality (4) planning from the beginning (5) the importance of time management (6) the role of the supervisor ((7) how academic and journalistic styles differ (8) my own experiences in supervision and (9)sources of feedback, are discussed.

\section{Contextual background}

I embarked on the doctoral programme on September 20, 2017. My first supervisor structured my initial programme into six parts. Part one was to focus on getting started; the introductory remarks talked of theorisation from the practical to the metaphysical as being what was expected of a doctoral study. Ironically, writing in simple language is often hyped but the language was sufficiently intimidating. The second part of the proposal would involve discussing the modalities with the 
supervisor and would be done in phases starting with the synopsis. The third phase would consist of fieldwork; part four was slated to be on data processing and analysis; part five, on report writing and the emphasis would be on the process, output and as the supervisor put it, "it would involve "everybody", meaning the research community. The last part would culminate in the viva voce and publication of the thesis. The first stage involved reading and discussing with the first supervisor what the doctorate is all about and being initiated into the writing for publication culture. This article is part of that process which was slated to take six months at the end of which a synopsis was to be conceived but has in one and a half years not been concretised. The article does not contradict what both the supervisors and students may already know but focuses on the modalities of supervision and being supervised; it does not even pretend to provide perfect remedies but labours to highlight similar contrasts and differences in perception and practice. The conflation of views, observations and suggestions regarding postgraduate supervision is considered a humble but needful contribution to the field of postgraduate education and should be shared. Doctoral supervisees tend to find seemingly extraneous aspects of supervision like relationships and conflict trivial yet they influence timely completion of the $\mathrm{PhD}$ programme.

Although belief in the kind of normal progress so characteristic of all postgraduate programmes is equally central, timely completions are not often the norm; the doctoral journey, described by Moxham et al (2016), as 'a marathon and not a sprint' is without doubt daunting. This begs the question: what are the theoretical and practical aspects of the numerous factors that influence successful and on-time completion which need to be understood, internalised and implemented to enable timely completion? According to Moxham et al (2016), a significant enabler or disabler of, and sometimes major, obstacle to timely completion is the supervisory relationship. If traditional supervisor-centric relationships are being challenged, the question is why? According to Picard et al (2010:21) universities are being urged to embrace contemporary research educational approaches instead of perpetuating transmissive approach to learning. One wonders which supervision style (Taylor and Kiley, 2015:180-192) is conducive to successful and timely completion. For example, would it be (1) laissez-faire style where it is assumed students are capable of managing both their study and self (2) pastoral style that assumes students can manage the study but need personal support (3) directional style that assumes that students require support in managing the study but not themselves or (4) contractual style that assumes the need for both personal and project support? Connell and Manathunga (2012:5) suggest a supervision style where the relationship is close and mutually respectful regardless of the inevitable difficulties. In my opinion, a supervision relationship that starts with the rules related to supervisor-student relationship such as ways of communication being made clear right from the beginning would be on the right path. The supervisor as an academic guide or mentor does not entirely preclude the existence of challenges. 


\section{Articulating expectations about supervision}

Bentley (2006) advises those starting on a $\mathrm{PhD}$ programme to borrow copies of the previous $\mathrm{PhD}$ theses of successful students to read in order to get an idea of what is expected. Phillips and Pugh (2010) discuss at length how to become a fully professional researcher and the skills such as presentation and public speaking. They suggest working as a team including negotiating and seeking both sides of any argument. I harbour no illusions whatsoever about the hardship of the journey leading to a $\mathrm{PhD}$, either by academic or professional nomenclature. Suffice to mention that colleagues in the "taught $\mathrm{PhD}$ programme" confirm the trepidation associated with studying for a Research Higher Degree because, as they metaphorically put it, "it is a marathon and not a sprint" (Moxham et al, 2016: 143-156). The observation that numerous factors influence successful and on-time completion is shared by several other scholars as well as those who have gone through the experience of enduring the seemingly insurmountable vicissitudes of such a journey.

\section{The dynamics of timely-completion of a PhD programme}

A focus is made on what was contended by Moxham et al (2016) that timelycompletion is significantly related to the early articulation of Supervisor-Student expectations on the one hand, and mutual complementarity of ideas as well as character, on the other. This occurs if a positive research higher degree programme involving possible co-authorship of journal articles enables the nurturance of novice researchers. The ideal type becoming the centre of controversy notwithstanding, the first question that emerges from the authors' unwillingness to pronounce themselves on which supervisory style (between the laissez-faire, the pastoral and directional styles, when they advise that the "right" style depends on the supervisor-student "fit") is, what is their preference?

However, their allusion to the quality and quantity of supervision having a significant impact on the doctoral experience, supervisors being responsive to student needs and viewing a doctoral programme as a human educational relationship. They argue that "one which is close and mutually respected inclusive of the inevitable ups and downs" seems to suggest a preference for the supervisor taking an active role in the teaching and pedagogy of research. Because none of them causes discomfiture to the serious learner, this author has no hesitation pronouncing a preference for mixedmethods (Johnson and Onwuegbuzie, 2004) and triangulation styles at the different stages of the supervision and research process itself. The pertinent question that now arises is whether it would be wise to discard the traditional supervisor-centric relationship. The answer is in the negative, there being instances when during the programme, commitment either by the supervisor or the student begins to falter due to sundry reasons some of which are paltry while others quite serious and have the potential to derail the efforts of both. The supervisor has to salvage the project even 
though, without doubt, the student ultimately takes the Lion's share of responsibility for late-completion or withdrawal. If successful on-time completion is to be achieved (Moxham et al, 2016: 145), time, vigour and commitment are from the supervisor and student's point of view quite necessary.

\section{The central phenomenon of incongruence of expectations in a supervisory environment}

The idea that the supervisor and the $\mathrm{PhD}$ student should aim at the same target is notoriously normative but at the same time presumptive because, as Moxham et al (2016) have acknowledged, expectations and needs vary widely amongst individuals, and are not static. Moreover, the basis or motivation for expecting may not be the same. The questions that would have been left unanswered with regard to the reality of this dichotomy would have to do with how to manage the delicate balance between the basis for expecting and concerns about the inevitable distinction thereof is not in theory alone but is neither derivative or dependent and exists of necessity. What lessons can the novice researcher derive from the flaws in their conception of expectations? Moxham et al (2016) provide a timely answer as to how best to meet the needs of this dynamic, to understand and appreciate the existence of subjective expectations at the beginning of the journey.

It is important to focus on strategies to support how the expectations from the supervisor and the student can be met. They include the need for regular communication, feedback, sharing criteria for quality, establishing a positive research culture but students expect supervisors to be friendly and supportive. A positive and trusting relationship and environment neutralises the challenges of differences in expectations between supervisors and the doctoral student. Apart from differences in the personality characteristics of both the supervisor and the supervisee that can impede understanding and appreciation of subjective expectations, it is not possible that incongruence will invariably result into unexpected negative consequences.

Ngabirano (2010) contends that negative descriptions of differences can degenerate into the kind of stereotyping that prompts some supervisors to perceive some supervisees as grumpy senior citizens needing careful handling and the young ones as ideal students who can always be beaten back to the right path but vice versa can also be true. Contention that on the positive side social institutions can provide support for experiencing certain values and worldviews but that both of those aspects create tension between who should be embraced and who should be excluded is instructive. Getting it right, therefore, needs identifying the challenges at an early stage to avoid the unintended consequences of incongruence, or at least to minimise them.

If research supervision is so bumpy and uncertain, as Moxham et al (2016) and Friedrich-Nel and MacKinnon (2016) observe and as this writer has come to learn, what can be done to smoothen the $\mathrm{PhD}$ by research pathway for enhancing successful and timely completion? The systematic approach advocated by experienced 
supervisors was also preferred by an unusual intellectual, Karl Max, whose ideas in the contribution to a "critique of political economy" which greatly influenced communist ideology. Max insisted, "the concrete could not be understood without being analysed", systematically into the abstract relationships which made it up (Mandel, 1962). The research work plan, for instance, needs to be broken into a series of smaller projects. With regard to 'gradual concretisation', Bentley (2006) is in tandem with Karl Max's generic ideas. He advises that the most effective way of achieving this is to periodically set a new target every 2-3 months. However, others suggest six months and that the target should have a clear result, that is, an article, a scientific paper, a literature review, among others, in order to create an environment in which the research student always has something to look forward to, a target to aim for every day.

By seeking a $\mathrm{PhD}$, students embark on an enterprise characterised by both an intense personal and professional relationship with their supervisors. The experience is different from previous academic relationships, because research students take up much more of the supervisors' attention, time and space. Likewise, the supervisor is more important to the supervisee than the undergraduate project supervisor, who was only one member of staff among many. A good relationship between a supervisee and the supervisor needs work by both parties. I personally have difficulties accepting the notion that it is not the supervisor's responsibility to make everything all right. Nevertheless, I agree with the prudence of forging an environment in which both can amicably work together. Many doctoral students encounter unnecessary problems because they make classic mistakes in dealing with their supervisors. According to Rugg and Petre (2004), most students ignore to think the relationship through.

They observe that most supervision problems are predictable and preventable. I agree with the former but not the latter. No matter how hard one tries some supervisors are as unmovable as the students they are supposed to move. However, the earlier the doctoral supervisee starts thinking things through the better. If they have already done so, then they will be much more likely to be viewed as an asset to their supervisors and the department, and are likely to finish with a successful conclusion. That most $\mathrm{PhD}$ horror stories have their origins in the supervisory relationship rather than in the research topic or the external examiner as Rugg and Petre (2004) contend, is true and worth noting. The most common cause, they maintain, is that the supervisee did not take the supervisor's instructions. Less common, though unknown, is the horror of an incompetent supervisor. The current practice is for $\mathrm{PhDs}$ to be supervised by more than one supervisor, which reduces the risk of having a difficult, slow, unwilling or incompetent supervisor. Departments usually pay keen attention to students' performance at the different stages of the doctoral journey, such as the transfer seminar where incompetence can be spotted, investigated and subsequently addressed. While not impugning that my supervisors are any of the above, I sought enhancement by attending a three week residential training course in Advanced Multimethod and Policy-oriented Research organised by the Nairobi-based Partnership for 
African Social and Governance Research Organisation, was attended by 42 participants from 25 universities across Africa. All those, including myself, presented research concepts mostly from $\mathrm{PhD}$ theses for those who were already $\mathrm{PhD}$ holders or Proposals for those who were doctoral students or candidates. The concepts were defended and thereafter subjected to intense academic rigour resulting into reconceptualisation and recrafting of the originals. Whereas such engagements are not substitutes to traditional supervision, most universities encourage participation in international or regional academic fora such as conferences, training workshops and symposia. For some it is a requirement.

One important issue in supervision is compatibility. Supervisees cannot expect that their relationships will be equally straightforward with every potential supervisor they are assigned. It apparently is not the supervisor's job to cope with, as Gordon Rugg and his colleague put it, "every unpleasant idiosyncrasy of every idiot who wants to do a $\mathrm{PhD}$ with them". Whereas not all supervisors think that way it is unfortunate that some of them think that because they experienced hardship when they were on the same journey others must go through the same. On the other hand, must doctoral supervisees, because they are apprentices, and not customers who 'are always right', put up with old-fashioned bullish supervisors? However, on the subject of rightness, this novice invariably agrees with the view by Rugg and Petre (2004) that there is not a single type of 'right' student or 'right' supervisor, any more than there is a single type of a 'right' partner in business or marriage. There are various types of supervisors, and various types of students; each type of supervisor will be well suited to some types of students, and less suited to other types of students.

In mediating between supervisors and their students whose relationship is no longer harmonious, the people must be separated from the problem. In my previous profession of diplomacy, it is generally held to be true that the human element in negotiation can be its downfall or its key success. If people are hurt, frustrated and have their backs against the wall, they may cause the negotiations to fail. If they have a positive relationship, where trust has been built up and enhanced over a long time, they will work hard to see the mediation negotiations or for that matter, the research project succeed. In any situation when dealing with human beings, it has to be accepted that you are dealing with people with deeply held values and ways of seeing the world, strong feelings and different backgrounds. Figure 1 below is a five-segment graphic representation of the causes of common conflict. 


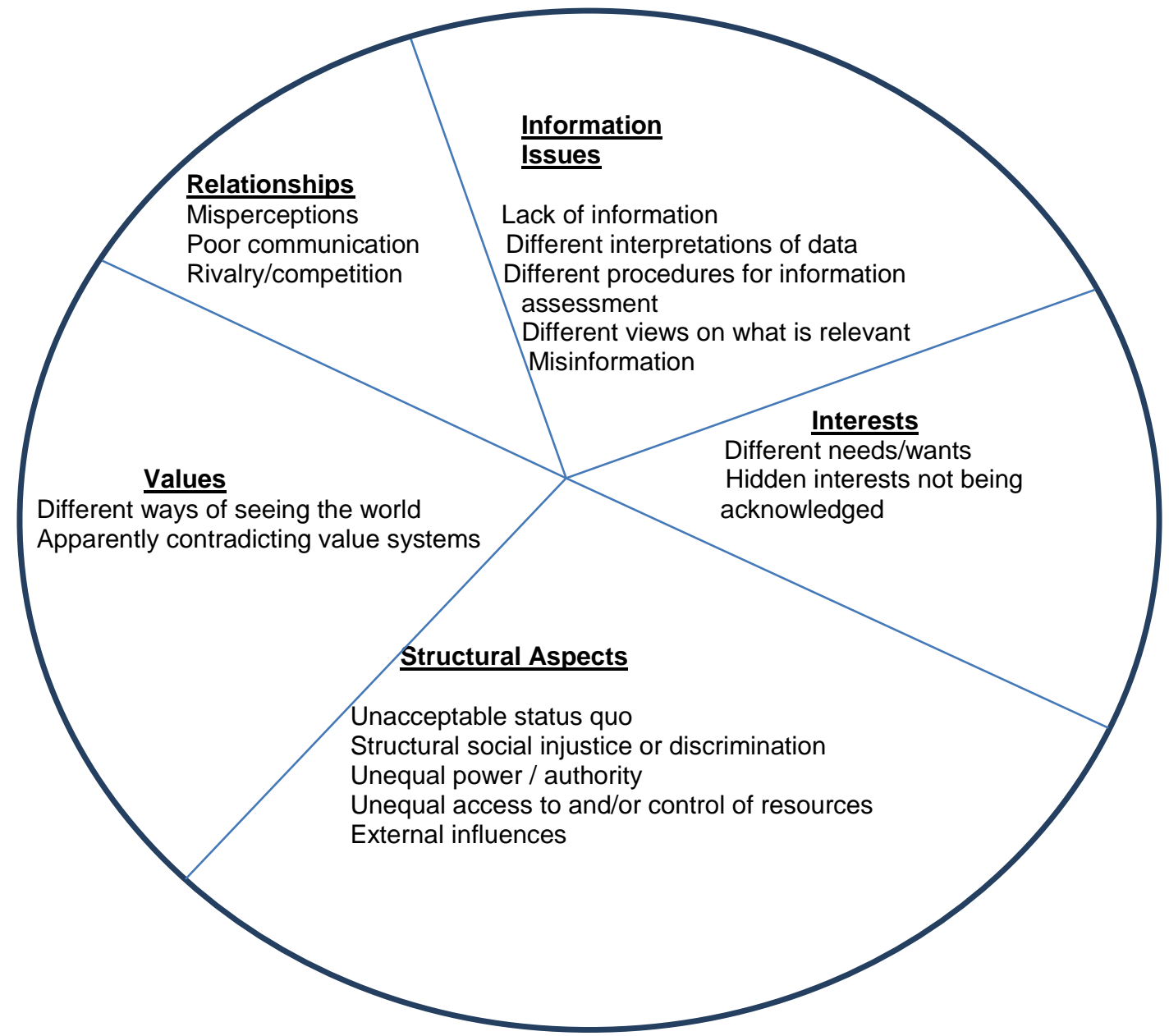

Figure1. The circle of possible conflict in the supervisor-student relationship Adopted from De Coning and Henderson (2008: 62)

Conflicts that lead to the supervisor-supervisee relationship to go wrong fit in the segment titled "Relationships" in the circle. Most conflicts actually have causes in every sector of the circle although some sectors tend to dominate. In a conflict, relationships often turn destructive and parties to the conflict demonise each other and fail to recognise each other as human. It is not always possible to know how the other person will react or what will affect them. An interest-based approach (De Coning and Henderson, 2006: 90-96) to exploring interests and finding solutions is based on four key principles designed to address relationship, procedural and substantive issues. They are (1) separation of the people from the problem (2) focusing on interests and not positions (3) inventing options for mutual gain (4) insisting on using objective 
criteria. A strategy in maintaining quality supervisor-student relationships is for individual supervisors to schedule occasional focus group meetings with all of their doctoral students. The feedback obtained at such meetings assists in shaping the process. The student ought to have the freedom to consult the supervisor at any time but the supervisor's time and space should not be unreasonably or improperly infringed. Ideally, the supervisor and the student should set specific goals at the beginning of the doctoral process and review periodically what has been achieved in a specific period.

When people act or set out on a journey they carry in their minds an image of what they want to achieve or where they want to go and how to get there. Human action sometimes involves carrying out projects designed to give effect to imagined ends; the achievement of which precludes that of other ends (Lachmann, 1970). The supervisor and the student choose what they want to achieve and make such a choice within the constraints and parameters of a given situation, which in this case is the supervisorstudent relationship. To move ahead, both have to make plans, carry out comprehensive surveys of the means at their disposal and the ways in which they will be used, and let their movement be guided by them. Is this not the reason for the $\mathrm{PhD}$ programme supervision project being a highly structured venture? Many people in academia would agree that it certainly is the case. Making clear the rules related to the supervisor-student relationship, establishment of clear goals and developing a symbiotic partnership based on mutual respect but at the same time not forgetting that the supervisor is "first-amongst-equals" as well as managing the research process as a joint venture invariably increases the chances of timely-completion.

As my supervisors and the university, twice [Bachelor's and Master's degrees] my alma mater decided that I have the potential to study and complete a $\mathrm{PhD}$ programme, it is not for me to maintain or give the impression that they could have been mistaken. Nevertheless, I have had the challenge of deciding when, how and on what particular challenges to seek guidance when in doubt about how to proceed on the initial assignments given to me with insufficient clarification of expectations. A student remains a student whatever their background might be, there being no such thing as the dilemma of a 'knowing student' working with a 'knowing supervisor'. Without adequate guidance at the beginning, frustration can easily manifest itself resulting into premature withdrawal. Frequent communication and clarifications are without a doubt necessary. The supervisor and the student need to agree on a mutually convenient time schedule to read the student's work and to provide feedback. This assists the supervisor to determine the student's needs and the student to determine whether they are making progress or not.

\section{Discussion of the findings carried out in the Australian study}

The discussion in Fourie-Malherbe (2016:143-169) rightly points to the necessity of selecting a topic and methodology; developing a study programme and time-table, 
progress, assistance and consistency of work; knowledge and a warm, supportive relationship; practical implications, limitations and conclusions. They are all pertinent to the supervision of a $\mathrm{PhD}$ programme because a research project relies on empirical data that remains valid until proven otherwise by subsequent research. The authors seem to be accomplished scholars and the methodology, including the data analysis procedure they used was robust enough to elicit reliable results. The study and subsequent discussion by Moxham et al (2013:345-354) is based on an online survey at universities across Australia, UK, Hong Kong and USA in which a purposive sample of research higher degree supervisors and candidates participated via the online Survey Monkey. A majority of supervisors had held their PhDs for over 10 years and had been supervisors or co-supervisors for between one and six students. Of the 607 candidates, only 65 per cent had attended a research higher degree orientation session, and 20.8 per cent had changed their supervisors. Varieties of reasons, some of which are discussed in this paper, were given for changing their supervisors.

Suffice to ruminate over whether the method of presentation of the findings could have differed in form from that of the inquiry the researchers in the Australian study carried out because the latter tends to appropriate the research material in detail, to analyse its different forms of development and to trace out their inner connections. It is probably only after work is done and experienced that supervision can be more adequately described. It is apparent that a verbal presentation that restricts itself to summarising more or less accurately can be insufficient, primarily from the standpoint of this novice researcher trying to learn the rigour of critical analysis required of a PhD level chapter review.

The apparent endorsement to the assertion in Bruce and Stoodley (2008: 1-31) that various supervisors across a range of disciplines determine their awareness of supervision as teaching must be interrogated. They perceive their role as one of making an impact on academic expertise and upholding academic standards. Their perspective is probably shared by many experienced supervisors but begs the question as to what their response would not be to the classic quotation by Shaw (1971: 80). He said, "The trouble with people is not that they don't know but that they know so much that ain't so". Its meaning is in tandem with the view that $\mathrm{PhD}$ students do not enrol in a research higher degree programme with a blank slate (tabula rasa). Johnson (1976) observed that knowledge is of two kinds. We know a subject ourselves or we know where to find information upon it but the veracity of this hypothesis varies from one doctoral student to another. This applies to both the supervisors as well as the students. It makes guidance, especially during the initial stages, by experienced supervisors variably necessary. After all, if students knew what to do and were knowledgeable, why would they choose a supervised taught $\mathrm{PhD}$ programme instead of the less rigorous on-line DL [distance learning] versions available worldwide?

Little wonder then that regarding responsibility for the standard of the thesis, the findings in the Australian study showed that candidate's expectations regarding who should decide on the standard of the thesis were significantly higher than the 
supervisors. Whereas 55.4 per cent of supervisors believed decisions regarding the standards of the thesis were mainly their responsibility, 45.4 per cent of the students believed it to be a joint and equal responsibility. I subscribe to the latter and a related one about who should ensure that work is progressing at an appropriate rate but withdraw support to the view that supervisors should only accept a candidate when they have specific knowledge about the student's chosen topic. This is in spite of the fact that in the Australian study by Moxham et al (2013: 345-354), both candidates and supervisors (72.9 percent) reportedly strongly agreed. Overall, the analysis of the results seems to be wanting but the substance of the findings is instructive and valid.

\section{Mutual expectations in the postgraduate doctoral supervisory relationship}

There seems to be no tension or dichotomy between the substance of Moxham et al (2013) Australian study and Friedrich-Nel and Mackinnon's (2016) South African experience, over the same topic. Both study reports highlight the necessity of formulating strategies for timely completion, which includes open and continuous communication, timely and constructive feedback but the latter are more emphatic on the requirement of the supervisor playing the role of academic guide and mentor. They both do not preclude the existence of challenges. The "supervisor-student fit" is delusionary. How does either of them determine that the fit is perfect? Besides, the supervisor as academic guide and mentor does not preclude the existence of challenges associated with the student's feelings of isolation, frustration and uncertainty, which supervisors sometimes ignore. Yet the supervisors also occasionally experience the anomie of a magnitude that can be transferred to the supervisor-student relationship. The Merriam-Webster's Collegiate Dictionary (2004) describes anomie thus: social instability from breakdown of standards and values, personal unrest, alienation and uncertainty that comes from lack of purpose or ideals. For instance, the development of hitherto unanticipated but potentially disjunctive errors that can cause a mismatch could interfere with the establishment of a good working relationship.

Another challenge could emanate from the inability of both supervisor and student to manage time effectively. It is not common for appointments for meetings not to be honoured by either party such as the supervisor turning up late or the student not turning up at all. Strategies for managing mismatched expectations must be devised. As Amin (2005) advises, ascertaining the causal relationships should not be expanded to other levels. For example, when evidence of the mismatch stems from individual weaknesses or traits, generalisations should not be allowed to engulf the entire research team or vice versa, should it? Both report on time management as being the key to completing a $\mathrm{PhD}$ programme on time but concrete recommendations on how to do it are conspicuous by their absence in the strategies they advocate.

The need for supervisor and student to work together is restated more emphatically in Friedrich-Nel and Mackinnon's (2016) chapter in a different publication. The 
supervisor-centric style school arguments are enhanced by the observation that by assuming the role of mentor, they need to assist the student in developing personal attributes. Such attributes include(1) ability to communicate effectively (2) think critically (3) practice self-discipline (4) be resilient (5) work independently (6) manage time effectively (7) sharing criteria for quality and (8) establishing a positive research culture. It is worth noting that most researchers on doctoral supervision, however different their points of view on other aspects might be, usually agree on the need for a positive supervisory relationship. Moreover, as most senior supervisors maintain, the ideal situation is often created when the student and supervisor set specific goals at the beginning of the doctoral education process (Moxham et al, 2013:144-147; FriedrichNel and McKinnon, 2016:159-161). A problem develops when the supervisor's goals are not in tandem with the supervisee's yet the former is supposed to provide practical guidance. Besides, some supervisors find themselves "spread too thinly" and unable to provide adequate support (Francis et al, 2009).

\section{Review of the results of the case study carried out in the USA}

A qualitative case study in which a sample of 38 individuals consisting of 23 postgraduate supervisors and 15 doctoral students was used by Friedrich-Nel and McKinnon (2016:161-162) informs this article. The study, which followed a structured interview approach, involved the perceptions of postgraduate doctoral supervisors and doctoral students with regard to supervision and was conducted at a research-intensive university in the USA. Friedrich-Nel and McKinnon (2016:161) claim the findings are in tandem with international research on doctoral supervision and generalisable to the South African experience. My first concern is about the size of the sample. Doctoral studies are a complex phenomenon deserving, not a very big sample size but no doubt one that is generalisable to many situations across the globe. It is too small to be "internationally aligned" or generalisable to the South African context. The sample size does not fit the geographical scope mentioned in the report. Doctoral students starting their studies are not all in the same situation. Since the information was electronically gathered via e-mail, a larger and more representative sample could have been possible. Moreover, given the different levels of development in the USA and South Africa, the statistical realities of sample size determination, generalising an American study to the South African context is contestable.

Nonetheless, it is of great academic interest that there is a curious correlation between the viewpoints of the USA study and the Australian one. Unfortunately, the scholars who carried it out could have used mixed methodology whereby statistical correlation tools would have quantitatively established the significance of such correlation through verification of some appropriate hypotheses. The report that "with regard to engaging in research leading to a thesis, supervisors expected students to identify a research problem, formulate the research question, and design the methodology" can be obtained from the postgraduate research handbook of any 
reputable university without interviewing just a paltry 38 individuals' participation. Even though the study may have been a pilot one, a wider geographical representation covering other continents would have been possible through the internet.

The resemblance of the research themes between the South African experience and the Australian as well as the USA Studies calls for a closer look to determine what the common ground, if any, is. The scholars could have done us a favour if they had identified variation in themes, that is, comparing differences and similarities of the themes in the collected data, traced possible developments and used clear descriptors. The use of quotations to illustrate some points and presenting summarised narratives did not salvage the need for more rigour. For instance, there is a strikingly closer correlation between the expectations of the students in the American and Australian studies on issues such as the need for the supervisor to provide leadership as well as acting as mentor, support from the supervisor throughout the research process, and the need for timely feedback from the supervisor as a means to shape their work. Others include students keeping the supervisor informed of their progress, meeting deadlines, being respectful of the supervisor's time schedules, the need for constant communication and consistency, adhering to comments on the constructive feedback, submitting professional-looking work for good quality, among others (Friedrich-Nel and Mackinnon, 2016:164-167).

\section{The necessity for frequent meetings and discussions}

The suggestion of the necessity for frequent discussion sessions on specific and relevant topics with the aim of strengthening the supervisory relationship indicates a positive academic policy interest in the findings of both the Australian and USA studies. Dunn (1981: 35) defines policy analysis as "an applied social science discipline which uses multiple methods (triangulation of inquiry and arguments) to produce as well as transform policy-relevant information that may be utilised in political settings to resolve policy problems." Although policy-related research often draws on interviews and it is true that interviewing can be the sole source of data for a qualitative-interpretive study (Fischer et al, 2007), using just one instrument (interview) for collecting data, therefore, undermines the potential policy value of the findings. Once the researchers had the data, why did they, among other approaches, not adequately analyse them interpretively?

The suggested topics forming a common ground for discussion are sharing students' and supervisors' backgrounds; sharing role expectations and responsibilities; creating timelines and collaboratively setting long term and short term goals; reviewing progress; resolving conflict and preparing for examination. These aspects of doctoral supervision are conspicuous for their realism and are crucial. They are a kind of tool-kit to be carried on the supervision journey, which most people testify paying attention to, and implementing them can and this author confirms describing it as "bumpy" is an understatement. Guiding the traveller on the doctoral journey should be 
motivating and ought to instil mutual trust and respect, without which proper briefing and debriefing about what to expect when taking the initial footsteps can be so frustrating that the unresolved can withdraw or fall by the wayside.

Equally important is the commitment of the so-called $\mathrm{PhD}$ "travellers" and those who guide them. It is not certain though, what Friedrich-Nel and his colleague meant by "a safe environment in which critical thinkers and problem solvers are nurtured and respected is created". Could it be a concern reflecting lack of academic freedom in some countries in the developing world where peremptory dictators control freedom of expression because of the "contagion of the example of dissent" spreading to supervisors? While Uganda may not yet be under the throes of such a constricting situation, there are signs, such as stepping-up repressive measures against journalists including those working for media houses owned by the state and to a lesser extent against academicians aiming at controlling the expression of independent opinion, the country could be dangerously veering towards that direction.

There is another problem; both the Australian and USA studies do not offer sufficient insight into how differences arising out of the supervisor-student so-called 'perfect fit' can be resolved. The administrative and social framework for resolving differences and managing conflict at universities might have been inadequate. Was it not a concern of the researchers who were seemingly so interested in nurturing a positive relationship? How could the researchers in both studies forget that relationships and viewpoints are not at all times purely intellectual? Psychological research indicates that people are more likely to attribute causality to others when their actions affect them than if they were to be mere observers. They even attribute wilfulness to inanimate objects and natural events like the weather, which is sometimes unpredictable if their failure or an occurrence affects them strongly enough (Bobbitt et al, 1974). If you have driven a car in Uganda's capital city Kampala recently and experienced or witnessed an accident at a traffic jam caused by disregard of the traffic lights by not only the motorists, motorcyclists and pedestrians alike but the traffic police officers too, you may understand the dynamics of chaos. The perception is that it is always the other driver who caused the accident.

By the same token, it is not uncommon for research students to attribute their failure to complete on time or do certain things to perfect their dissertations to the supervisor and vice versa or for the supervisor to betray their students with the claim that the supervisee was uncooperative during a Masters Viva Voce or PhD public defence forum. The implication is that the supervisor and student must simultaneously view themselves both as partners in a joint venture or a part of a behavioural causeeffect system and at the same time independent of it! The researchers should have included a question in the interview guide to elicit views on how to manage conflict, perceived or real. Shouldn't they have done so? Issues of scope notwithstanding, another omission relates to the dynamics of research supervision.

The discussion offers no insight into different types of relationships whose dynamics may have influenced the supervision of the research projects. The first 
concern is over the relationship between the student researcher and the respondents. The second concerns the relationship between researcher and fellow researcher when the research teams undertook the projects. The issues might partly stem from the need to know whether ethical standards regarding autonomy, beneficence, justice, identification, disclosure, deception, voluntariness, competence, informed consent, anonymity, confidentiality, integrity, among others with regard to the first relationship; and sometimes importantly ascription of authorship, rights to use the research material of a student and use of authority/role are critically observed (Amin, 2005).

\section{Supervising the writing of a dissertation}

Gottlieb (1992) follows in the footsteps of many others to articulate the issue of noncompletion or delayed completion of a research higher degree. There are several possible explanatory contributing factors to absence of on-time completion; among them, the fact that the student may be working in isolation, like I initially did inadvertently annoying the second supervisor, rather than as a member of a research team. The contributing factors to longer completion times at the University of Queensland include isolation from other students and staff (other than supervisors); which leads to total dependence upon the knowledge, skills and whims of the supervisor. Others include lack of coordinated training in research methodology skills in Universities experiencing quality assurance challenges where the teachers themselves need to be taught and the unreasonable amount of time squandered or legitimately spent settling into the topic at the beginning of the candidature.

\section{The centrality of academic conviviality}

Conviviality is related to being occupied with or fondness to feasting, drinking and good company but its last meaning can be applied to the research studentship environment. A sense of anomie and isolation which can set in at any stage of the commencement of a doctoral programme, the writing or later at the research stage, may be due to lack of "conviviality", which Montuori (2008) describes as a central part of creative inquiry that is characteristic of the $\mathrm{PhD}$ by research. He advises that inquiry always take place with others [colleagues] on similar doctoral programmes, whether they are physically present or not, with a student's predecessors in "different times and spaces, with friends and foes" who have approached the subject we are interested in currently or before us. He reveals that inquiry is increasingly conducted in research teams, conducted in a web of relationships, and connections with others, who may inspire, upset, enthuse or even repulse us with their actions. Whereas it makes a lot of sense to the research student in the Western world, it has not been readily embraced in Africa due to a number of reasons. For example, there is the fear that one's work can be stolen and sold to the highest bidder who then goes ahead to 
complete their own degree programme, as the original owner of the work continues to struggle to reach the finishing line. The phenomenon of ghost researchers is also on the rise nowadays. Hacking of computers that are networked in a convivial relationship further complicates the matter.

The policy of research teams having to follow similar research themes in the School of Arts and Social Sciences of the institution I work for as a lecturer, pitifully failed when academic staff refused to conduct research within the research groups they had been assigned to, claiming that the grouping criteria had been faulty. They did not understand either how group research works or had other issues they did not want to openly articulate, preferring instead to turn the research group system into a scapegoat. The otherwise good idea was subsequently abandoned. It is not too late to pick it up where it was rested.

\section{The imperative of planning the supervisory journey from the beginning}

Embarking on a $\mathrm{PhD}$ is an intellectually demanding enterprise. The usually neglected yet obvious need for careful planning is once again highlighted here. The second part is planned to be reading and discussing how to search for and review literature on the proposed area of interest before coming up with the research topic. I have been warned to be ready to change dogma; being open to the possibility of change along the way and not fixing one's mind on any paradigm when it becomes necessary. In fact, Professor Musaazi $^{2}$ advised against mechanistic procedures that might involve traditional ways of identifying dependent and independent variables emphasising the need for moving from reproductive mode to creative application and that the research problem can be conceived differently. The literature review will include seminal, narrative literature, exploring research trends on conflict management, meta-analysis, meta-synthesis and positivity. I am provisionally enrolled as a novice doctoral student at Makerere University's College of Education and External Studies, and the methodologies are sufficiently flexible, adaptable and universally applicable. Plans can be changed and adapted according to the circumstances that exist (Musaazi, 2006).

A plan has to contain a comprehensive account of ends, means and obstacles to which a course of action is oriented. It provides the systematic framework of all points of programme orientation relevant to a given course of action. The "orientation map" is a necessary ingredient of the plan, which must also contain directives for action in space and time (Lachmann, 1970: 38). Gottlieb (1992) likewise contends that there are various approaches to the preliminary organisation of research also called research mapping, concept charting and research design. Other scholars, among them Watson

\footnotetext{
${ }^{2}$ Professor J C S Musaazi who is a veteran of graduate supervision and the most senior person on the teaching staff of the East African School of Higher Education Studies and Development at Makerere University. He is an expert in a number of educational fields of Higher Education and Educational Planning and Administration, and Research Methods. He has supervised numerous successful doctoral candidates.
} 
(1970), do the same. A good research roadmap should show the basis for the structure of the thesis in terms of chapters which in turn helps with the writing of the introduction and conclusion. It also helps to identify limits in terms of the time and size of the research project as well as the funds needed to complete. Devising a good $\mathrm{PhD}$ research roadmap, therefore, requires extensive initial brainstorming and rationalisation of the results into a logical plan.

\section{The importance of time management}

The importance of time management as an aid to completing the thesis cannot be under-estimated. It has been adequately articulated and reviewed in the previous sections of this paper. Noteworthy though, is the fact that successful time management depends on early specification and definition of the parameters of the research. The nature and scope of the topic ought to be clarified in the early stages of the project to enable construction of a clear research map and programme of activities; determining the order in which the different activities will be undertaken including the time that will be required to complete the literature review and drawing the research map. Good planning might involve outlining the objectives, why the proposed project would represent an original contribution, the outcome of the literature searches and preliminary bibliography and a tentative outline of the thesis.

\section{The importance of the role of the supervisor as a mentor}

The need for a supervisor to be a role model is again emphasised by Gottlieb (1992). According to Stoilescu and McDougall (2010) and Aitchison (2016:80-91), a supervisor who publishes regularly sets an example in practical terms and can adequately discuss the problems of writing, publishing and can offer advice to the supervisee on how to surmount them. This reinforces the concept and practice of collegiality, which is hyped throughout the literature on doctoral education. Continuing the time-management narrative, Gottlieb (1992), reiterates the suggestion by other scholars that frequent written pieces help the student get accustomed to writing about topics relating to the area of research while at the same time enabling the supervisor to identify weaknesses that require remedial action. She, like all the other writers and scholars, maintains that the major source of feedback is the supervisor who should be conscientious in providing written comments on submitted work even though generally doctoral students can and are encouraged to widen the area of consultation to other members of faculty. I initially wrote up to six papers all of which were rubbished on some technicality, omission, commission, or some such other shortfall or incongruence to doctoral writing. They did not meet the expectations of the supervisor but it was and still is a great learning experience, which once internalised can never be forgotten. 


\section{The importance of learning academic writing styles from the supervisor and the research community}

Even though newspaper articles by a columnist involve committing ideas to paper on a regular basis, writing out at doctoral student level requires different skills, which can only be perfected through submitting regular written pieces to supervisors for their attention and necessary action. Gottlieb (1992) suggestion that all written material should be returned in good time with appropriate feedback is important because the students need to know whether they are on the right track or not; and if not, how to remedy the incipient and attendant weaknesses in a timely manner. Moses (1985) suggests regarding asking for regular written progress reports underscores the importance of feedback by both the supervisor and the student. Keeping a diary of progress is a good practice supported by Zubrick (1985) who, in the same vein, suggests keeping reading logs in which to record their personal reactions to whichever literature they might be reading at any one time.

\section{My experiences in supervising Bachelors and Masters' degree students}

During eight years, this author supervised 18 Masters and Bachelor's dissertations. The experience was daunting. In some cases, the Bachelors project reports were of better quality than some Masters dissertations. They contained errors requiring correction consistently because of failing to adhere to the rules of academic writing, spelling, grammatical mistakes, faulty punctuation, etc. It is not surprising that at $\mathrm{PhD}$ level, students should be, as it were, drilled into practicing or re-learning routine chores like ensuring that all typing errors have to be corrected before submitting any drafts; checking spelling mistakes, grammar, proper pagination, punctuation and choice of language befitting doctoral standards. After all, are PhD students not produced by the same educational system, which produces the Bachelors and Masters students, who make the horrendous spelling or grammatical mistakes? I am in complete agreement with the view by Gottlieb (1992) that the issues mentioned above are borne in the minds of the examiners. The supervisor does the student absolutely no favour by allowing the submission of sloppy work; they should insist on high standards right from the beginning. For elderly supervisees who are beginning to succumb to amnesia, the technique of pick-up points, keeping little memos to themselves at the point where they left off reminding them of what should come next is a "best practice" (Nightingale, 1992).

\section{Sources of feedback on how the doctoral students progress}

Timely feedback has been emphasised in all the literature on supervision. Ascertaining the major sources of feedback is, therefore, quite important. The first source is of course the supervisor who, as advised by Gottlieb (1992), should be conscientious in 
providing written comments on the submitted work. The other members of faculty can give feedback too, and apparently, supervisors encourage and expect it because it is an effective tool in overcoming the feeling of isolation as mentioned earlier in this article. When they are not trying to demonstrate superiority over new doctoral students, those nearing the end of the doctoral journey can also be good sources of constructive criticism.

\section{Conclusion}

This article has been an attempt at presenting a conflated picture of the very demanding postgraduate supervision environment, which requires supervisors and doctoral students by research to clarify and discuss their expectations at the beginning. Such clarification ought to be carried out on an ongoing and regular basis to avoid the number of both intended and unintended consequences such as late completion and problematic supervision relationships. It is clear from the various arguments, suggestions and insights into the nature and substance of $\mathrm{PhD}$ research supervision that the relationship between the supervisor and the student must be convivial. Early articulation and clarification of expectations is necessary. Time, vigour and commitment to establishment of clear goals are not only a good practice but also proven enablers of timely completion of the programme. Developing a study programme and timetable, steady progress, supervisor assistance and consistency of work is default setting for starting and staying onto a $\mathrm{PhD}$ programme. Knowledge and a warm, supportive relationship ought to be cultivated and fostered. Planning from the beginning including research mapping and concept charting are required. Proper time-management and internalising the criteria for examination of $\mathrm{PhD}$ dissertation such as providing a contribution of ideas to knowledge with a high level of originality, capacity to relate the research topic to the discipline, being clear, accurate and cogently written theses are useful. Encouraging the use of writing as a voyage of discovery enhances professional development. All the above aspects of doctoral supervision are invariably vital to the completion of a $\mathrm{PhD}$ by research and should be understood, adhered to and where necessary implemented or caused to be implemented by both the supervisors and their students.

The analysis and discussion has shown that to be effective, the study and research plan must be feasible. However, the differences in perception or procedure can present the supervisor and student with a practical challenge. If they have to solve a concrete issue together, difference is a huge obstacle to action. They have to agree, in order to act, and when they do not agree, differences often deepen down beneath the concrete issues, or broader orientations of the supervision plan. Despite the weaknesses of the main study reports that benchmarked this review of literature on postgraduate supervision and starting a doctoral programme, I have no hesitation to conclude that knowing the highlighted issues and challenges is invariably beneficial to the doctoral student and the supervisor. 


\section{References}

Aitchison, C., 2016. Research writing: Purposes, practices and pedagogies in contemporary times. In: Postgraduate supervision: Future foci for the knowledge society. Fourie-Malherbe., Albertyn, R., Aitchison, C and Bitzer. (Eds), Stellenbosch: Sun Press, 2016

Amin, E. M., 2005. Foundations of social science research: Conception, methodology and analysis. Kampala: Makerere University.

Bently, P. J., 2006. The PhD application Handbook. New York: Open University Press, McGraw-Hill, pp. 114-124.

Bobbitt, H. R, Breinholt R. H, Doktor R. H, and McNaul J. P., 1974. Organisational behaviour: Understanding and prediction. Englewood Cliffs, New Jersey: Prentice-Hall, Inc.

Bruce, C., and Stoodley I., 2008. Student resources for the use of supervisors: ALTC Fellowship, Australian Government Department of Education, Employment and Workplace Relations. [Online] Available from: http: //eprints.qut.edu.au/28585/1/student- resources.pdf [Accessed 30 October 2015]

Daniel, B., 2018. Assessing Rigour in Qualitative Research using the TACT framework. Lecture at a $\mathrm{PhD}$ workshop at Makerere University, College of Education and External Studies, 22 January 2018.

Dunn, W. N., 1981. Public policy analysis. In: Handbook of public policy analysis: Theory, politics and methods. Fischer, F., Miller, G. J, and Sidney M. S., (Eds), CRC Press, 2007

De Coning, C., and Henderson, I., 2006. Conflict management for peacekeepers and peacebuilders. Umhlanga Rocks, South Africa: ACCORD.

Fischer, F., Miller, G. J. and Sidney, M. S., (Eds)., 2007. Handbook of Public Policy Analysis: Theory, Politics, and Methods. New York: Taylor \& Francis Group, CRC Press

Fourie-Malherbe, M., Albertyn, R., Atchison, C., and Bitzer, E., 2016. Postgraduate supervision: Future foci for the knowledge society. South African SUN Media Stellenbosch.

Francis, K., Mills, J., Chapman, Y., and Birks, M., 2009. Doctoral dissertation by publication: Building scholarly capacity whilst advancing new knowledge in the discipline of nursing. International Journal of Doctoral Studies, 4, 97-106.

Friedrich-Nel H., and Mackinnon, J., 2016. Mutual expectations in the postgraduate doctoral supervisory relationship. In: Postgraduate supervision: Future foci for the knowledge society, Fourie-Malherbe., Albertyn, R., Aitchison, C and Bitzer., (Eds), pp, 157-169, Stellenbosch: Sun Press, 2016

Gottlieb, N., 1992. Supervising the writing process. In: Quality in Postgraduate Education, Zuber-Skerritt. O., and Ryan.Y., (Eds)., pp, 110-119.Brisbane: Tertiary Education Institute, University of Queensland, 1992 
Hicks, H. G., and Gullett, C. R., 1976. The management of organisations, $3^{\text {rd }}$ edition, Tokyo: McGraw-Hill, Kogakusha.

Johnson, R. B., and Onwuegbuzie, A. J., 2004. Mixed Methods Research: A Research Paradigm whose time has come. Educational Researcher, Vol. 33 (7): 14-26.

Johnson, S., 1976. Life. In: The Lexicon Webster Dictionary, Volume II. The English Language Institute of America, Inc., USA.

Lachmann L. M., 1970. The legacy of Max Weber: Three essays. London: Heinemann Mandel, E., 1968. Marxist economic theory. Volume I. London: Merlin Press.

Merriam-Webster's Collegiate Dictionary., 2004. $11^{\text {th }}$ edition, Merriam-Webster, Incorporated: Springfield, Massachusetts, USA.

Moses, I., 1985. Supervising postgraduates. HERDSA Green Guide No.3. Sydney: Higher Education Research and Development Society of Australia.

Montuori, A., 2008.The Joy of Inquiry. Journal of Transformative Education, Vol. 6 (I)

Montuori, A., and Donnelly, G., 2013. Creative inquiry and scholarship: Applications and implications in a doctoral degree. The Journal of Global Education. [Online] Available From: https://www.researchgate.net/publication/259184429_Creative_Inquiry_and_Schol arship_Applications_and_Implications_in_a_Doctoral_Degree [Accessed 18 October 2017]

Moxham L., Taylor, E., Dwyer, T., Lauder, W., Stephens M., Antoniou C., Roxburgh M., Reid-Searl., Chan, A. E., and Fuller, C., 2016. Articulating expectations about supervision, 143-156. SUN MeDIA Stellenbosch, South Africa.

Musaazi, J. C. S., 2006. Educational planning: Principles, tools and applications in the developing World. Makerere University, Kampala.

Ngabirano, M., 2010. Conflict and peacebuilding. Uganda Martyrs University Book Series, Kampala.

Nightingale, P., 1992. Initiation into research through writing. In: Starting ResearchSupervision and Training. Zuber-Skerritt, O., (Ed)., Brisbane: Tertiary Education Institute, The University of Queensland, 1992

Phillips, E. M., and Pugh, D. S., 2010. How to get a PhD: A handbook for students and their supervisors, $5^{\text {th }}$ edition, Open University Press: McGraw-Hill, 23-29, 3851.

Rugg, G., and Petre, M., 2004. The unwritten rules of PhD research. England: McGraw-Hill House, Open University Press.

Shaw, H. W., 1971. Josh Billings' Encyclopaedia of Wit and Wisdom. In: The English-Language Institute of America's, The Lexicon Webster Dictionary, Encyclopaedic Edition. Vol. II.

Stoilescu, D., and McDougall, D., 2010. Starting to publish academic research as a doctoral student. International Journal of Doctoral Studies, Vol. 5: 80-91.

The Lexicon Webster Dictionary., 1971. The English Language Institute of America, Inc., USA, Vol. II 
Zubrick, A., 1985. Learning through writing: the use of reading logs. HERDSA, Vol. 7(3): 11-12, 24.

\section{Author Biography}

Samuel Herbert Baligidde is a former career diplomat and is currently a Research $\mathrm{PhD}$ student at the East African School of Higher Education Studies and Development, College of Education and External Studies, Makerere University. He teaches at the School of Arts and Social Sciences of Uganda Martyrs University. He was a Director of East African School of Diplomacy, Governance and International Studies and a pioneer Director of Lubaga campus. He is also a member of the 8member-country Inter-Governmental Authority for Development's 21-member Mediation Roster. He has supervised several Master and Bachelor's dissertations at UMU. His current research interests are student unrest and staff industrial action, the causes of chaos at public universities, faith-based catholic universities' contribution to education for sustainable development, public diplomacy and foreign policy domestic linkages. 